\title{
Functional strength training and movement performance therapy produce analogous improvement in sit-to-stand early after stroke: early-phase randomised controlled trial
}

\author{
A. Kerr ${ }^{\mathrm{a}}$, A. Clark $^{\mathrm{b}}$, E.V. Cooke ${ }^{\mathrm{c}}$, P. Rowe ${ }^{\mathrm{a}}$, V.M. Pomeroy \\ ${ }^{a}$ Centre of Excellence in Rehabilitation Research, University of Strathclyde, Glasgow, UK \\ ${ }^{\mathrm{b}}$ Faculty of Medicine and Health Sciences, University of East Anglia, Norwich, UK \\ ${ }^{\text {c}}$ Therapies Department, St. George's Healthcare NHS Trust, London, UK
}

* Corresponding author. Address: Biomedical Engineering, Faculty of Engineering, University of Strathclyde, Wolfson Building, 106 Rottenrow, Glasgow G4 0NW, UK. Tel.: +44 (0)141 5482855.

E-mail address: a.kerr@strath.ac.uk (A. Kerr). 


\section{Abstract}

Objectives Restoring independence in the sit-to-stand (STS) task is an important objective for stroke rehabilitation. It is not known if a particular intervention, strength training or therapy focused on movement performance is more likely to improve STS recovery. This study aimed to compare STS outcomes from functional strength training, movement performance therapy and conventional therapy.

Design Randomised controlled trial.

Setting Acute stroke units.

Participants Medically well patients ( $n=93)$ with recent (<42 days) stroke. The mean age of patients was 68.8 years, mean time post ictus was 33.5 days, 54 (58\%) were male, 20 showed neglect (22\%) and $37(40 \%)$ had a left-sided brain lesion.

Interventions Six weeks of either conventional therapy, functional strength training or movement performance therapy. Subjects were allocated to groups on a random basis.

Main outcome measures STS ability, timing, symmetry, co-ordination, smoothness and knee velocity were measured at baseline, outcome (after 6 weeks of intervention) and followup (3 months after outcome).

Results No significant differences were found between the groups. All three groups improved their STS ability, with $88 \%$ able to STS at follow-up compared with $56 \%$ at baseline. Few differences were noted in quality of movement, with only symmetry when rising showing significantly greater improvement in the movement performance therapy group; this benefit was not evident at follow-up.

Conclusions Recovery of the STS movement is consistently good during stroke rehabilitation, irrespective of the type of therapy experienced. Changes in quality of movement did not differ according to group allocation, indicating that the type of therapy is less important. 
Clinical Trial Registration Number NCT00322192.

Keywords: Sit-to-stand; Functional strength training; Physiotherapy; Movement quality; Randomised controlled trial 


\section{$<$ A $>$ Introduction}

Standing up from a chair, bed or toilet is an unremarkable everyday movement performed repetitively. Indeed, healthy older people perform the sit-to-stand (STS) movement 71 times per day, on average [1]. High frequency should not, however, belittle the difficulty of the task. Older adults may be close to their maximal knee extensor strength during the rising phase of STS [2]. Add to this the coordination and balance requirement [3], and it is not difficult to understand why so many people, particularly those with paresis such as stroke survivors, have difficulty executing this important task. Loss of the ability to perform STS safely threatens the capacity to live independently, with consequent resource implications for healthcare and social care services. Retraining the STS movement is, therefore, an important focus of rehabilitation after stroke [4].

Evidence indicates that therapy to enhance recovery of STS should consist of task-specific functional training [5,6], and that strength training may enhance the benefit [7]. This combination of therapy is known as functional strength training (FST) [8]. Proof of principle for walking benefit has been found when FST was compared with no therapy in people between 36 and 120 months after stroke [9]. However, when FST was compared with conventional physical therapy (CPT) for participants receiving routine CPT early after stroke, it was the additional movement performance therapy (MPT), i.e. conventional physical therapy focused on movement performance (CPT + MPT), that had greater benefit for walking recovery than additional FST (CPT + FST) [8]. This may simply have been the result of the study being statistically underpowered; however, it is also possible that the MPT investigated was more beneficial than FST because it emphasised therapeutic techniques that focus on enhancing the quality of movement through use of sensory stimulation and muscle/joint preparation for functional movement [10]. Indeed, there is evidence that both therapeutic approaches are beneficial [11].

This paper reports additional findings from the published early-phase trial relating to whether $\mathrm{CPT}+\mathrm{FST}$ and $\mathrm{CPT}+\mathrm{MPT}$ (termed 'CPT + CPT' in previous work [8]) could have differential benefits early after stroke in terms of: (a) the ability to perform the STS movement; and (b) the quality 
of movement performance (timing, co-ordination, smoothness and symmetry) during the STS movement.

\section{$<$ A $>$ Methods}

Full details of the design of this observer-blind, multicentre, randomised controlled early-phase trial are provided in an earlier publication [8]. In summary, baseline measures were conducted with participants who were subsequently randomised to one of three groups: CPT, CPT + MPT or CPT + FST. The intervention period lasted for 6 weeks. Outcome measures were undertaken at the end of the intervention phase, and follow-up measures were taken 12 weeks later.

The local research ethics committees covering the clinical centres granted ethical approval. The trial was registered on a clinical trials database (NCT00322192).

\section{$<B>$ Participants}

All participants provided written informed consent and met the following criteria:

- $\quad$ aged $\geq 18$ years;

- between 1 and 13 weeks post stroke (haemorrhage or infarction);

- able to produce some voluntary contraction of paretic lower limb muscle (score at least 28/100 on the lower limb section of the Motricity Index [12]), and with potential to make clinically important improvement;

- able to follow a one-stage command;

- independently mobile, with or without aids, prior to the index stroke;

- no lower limb orthopaedic surgery or trauma to the lower limb in the previous 8 weeks; and

- no previous history of neurological disease other than stroke.

\section{$<B>$ Interventions}


All participants received routine CPT from the clinical therapists. This averaged 9.2 hours [standard deviation (SD) 6.9] for the CPT group, 7.4 hours (SD 8.6) for the CPT + MPT group, and 8.9 hours (SD 8.2) for the CPT + FST group over 6 weeks. Using a therapy protocol [13], research therapists provided the additional experimental FST and MPT, as allocated. The experimental therapies were provided for up to 1 hour per day, 4 days per week for 6 weeks. This gave a possible total of 24 hours of additional therapy; however, the actual total intervention durations were a little less [23.0 (SD 10.4) hours of CPT + MPT and 23.5 (SD 10.0) hours of CPT + FST]. A detailed description of the experimental MPT and FST is provided in the earlier report of this trial [8]; therefore, only an outline is provided here.

The experimental MPT focused on those interventions in the treatment protocol [13] that emphasised control and quality of movement. This was predominantly hands-on therapy that included sensory stimulation and preparation of body segment alignment prior to practising functional tasks, such as STS, walking, and standing with supervision and feedback.

Experimental FST focused on repetitive progressive resistive exercise during goal-directed functional activity. The emphasis was on producing the muscle force appropriate for the functional activity being practised. Treatment was progressed systematically using repetition and increase in resistance by, for example, changing the limb's relationship to gravity, increasing the range of movement or distance over which body weight was transported, and changing the weight of external objects.

\section{$<B>$ Measurement of outcomes}

The earlier paper [8] reported walking outcomes, and the present paper reports outcomes related to the STS task. The primary outcome was ability to perform the STS task, and the secondary outcomes were: time to perform the STS task; smoothness of movement during the STS task; co-ordination of movement during the STS task; kinetic symmetry during the STS task; and maximum knee angular velocity during the STS task. 
All measurements were undertaken in a movement analysis laboratory.

\section{$<B>$ Data capture and processing}

Participants were asked to stand up from a plinth, the height of which was adjusted to $100 \%$ of their knee height. No assistance was provided, although a physiotherapist supervised the session. Participants were instructed not to use their arms; any attempts that included the use of arms were considered as failed attempts and were not included in the analysis.

Reflective markers were attached to each body segment (head/trunk/arms/hands/thighs/lower legs/feet), and tracked with a three-dimensional motion capture system (Vicon, Oxford Metrics, Oxford, UK) which has reported accuracy $<0.6 \mathrm{~mm}$ [14], intrarater reliability $>0.8$ (ICC) [15] and a standard error of measurement $<5^{\circ}[15]$. The participant's feet were placed on separate forceplates to record ground reaction forces throughout the movement. This arrangement allowed the reconstruction of a three-dimensional kinematic and kinetic model for each participant, so segmental and total body biomechanical variables could be extracted.

Data were captured at $120 \mathrm{~Hz}$, processed by filling gaps in the marker trajectories (Woltring, maximum gap 5) and then applying a digital filter (fourth-order Butterworth, zero lag, cut-off $6 \mathrm{~Hz}$ ). Once processed, the data were exported to a spreadsheet (Excel 2007, Microsoft Corp., Redmond, WA, USA) for calculation of the quality of movement variables, as described below.

First the data were normalised in the time domain using movement onset and end events. Onset was defined as the first point of continuous forward movement of the total body centre of mass (CoM), and the end event was defined as the peak of CoM vertical displacement (i.e. the first time the body reached its peak height). The time for seat-off was recorded as the point when vertical forces exceeded their baseline for more than 20 frames. These time events allowed calculation of total movement duration (onset time to end time) as well as the two movement phases: flexion momentum (onset time to seat-off time) and extension (seat-off time to end time) [16]. 
Next, the quality of movement metrics were derived as follows.

- Smoothness - defined as the number of inflections in the horizontal component of the CoM jerk signal, with jerk being the third time derivative of displacement. The greater the number of inflections, the less smooth the movement $[17,18]$.

- Co-ordination - defined as the temporal overlap between the ipsilateral hip and knee angular displacement on the affected side. This was expressed as a percentage of the total movement duration [18].

- Kinetic symmetry - calculated as a ratio of the vertical forces recorded by the affected and unaffected side, respectively, at the seat-off and end events, as well as the period between these events (i.e. the extension phase period). To avoid mathematical anomalies that can occur in a simple division of one forceplate by the other, this ratio of kinetic symmetry was calculated as follows: $(2 \mathrm{x}$ affected side)/affected + unaffected $)-1$. Therefore, positive values would indicate a bias towards the affected side.

- Maximum knee angular velocity - defined as the maximum value from the software output (Oxford Metrics) of the first derivative the paretic side knee angle between onset and end.

- Movement duration: time (seconds) between the onset and end events [16].

\section{$<B>$ Statistical analysis}

The ability to perform the STS task was compared between the treatment groups $(\mathrm{CPT}, \mathrm{CPT}+\mathrm{MPT}$ and CPT + FST) at outcome and follow-up using Chi-squared test and logistic regression.

All other measures were analysed by examining only those individuals able to complete the task, and using a regression model with 'group' as a fixed factor. This allowed a comparison to be made between the CPT group and the CPT + MPT group, and also between the CPT group and the CPT + FST group. 


\section{$<$ A $>$ Results}

$<B>$ Flow of participants through the investigation

The CONSORT flowchart for the investigation shows that 109 stroke survivors undertook the baseline measures for the main trial (Fig. A, see online supplementary material). Of these participants, 15 were recruited from a clinical centre that did not have access to the movement analysis laboratory, and STS data were not collected for one participant. Consequently, 93 participants undertook the STS measures at baseline. Of the 93 participants, 32 were allocated to the CPT group, 31 were allocated to the CPT + MPT group, and 30 were allocated to the FST + CPT group. At outcome, 10 of the 93 participants had withdrawn (11\% of 93), and at follow-up, a total of 26 participants had withdrawn (28\% of 93). The reasons for loss to outcome and follow-up are provided in Fig. A (see online supplementary material).

\section{$<B>$ Characteristics of participants at baseline}

The baseline characteristics of all 93 participants are described in Table 1. In summary, the mean age of participants was 68.8 years, mean time post ictus was 33.5 days, 54 (58\%) were male, $20(21 \%)$ showed neglect and $37(40 \%)$ had a left-sided brain lesion.

At baseline, 52/93 (56\%) participants were able to perform the STS movement. The data from three participants were excluded due to forceplate encroachment by the supervising physiotherapist $(n=1)$ and large gaps (>15 frames) in marker tracking $(n=2)$. Details of the 49 participants included in the STS performance analysis are included in Table 1.

\section{<Insert Table 1 near here>}

\section{$<B>$ Ability to perform the STS task}

There were no significant differences between the groups at baseline in terms of their ability to perform the STS task: CPT group (20/32, 63\%), CPT + MPT group (16/31, 52\%) and CPT + FST 
group $(16 / 30,53 \%)$. The total number of participants able to perform the STS task increased from $52 / 93(56 \%)$ at baseline to 66/84 (79\%) at outcome and 60/68 (88\%) at follow-up (Table 2).

At outcome, there was a non-significant trend for both extra therapy groups to have a higher proportion of participants able to perform the STS movement than in the CPT group. The odds ratios were 1.85 [(95\% confidence interval (CI) 0.52 to 6.63] for the CPT + MPT group, and 2.11 (95\% CI 0.59 to 7.47 ) for the CPT + FST group. These possible benefits were not evident at follow-up, with ORs of 0.28 (95\% CI 0.03 to 2.72) and 0.41 (95\% CI 0.04-4.26), respectively.

\section{<Insert Table 2 near here>}

\section{$<B>$ Quality of movement during the STS movement}

The number of participants included in this analysis across the three time points changed according to: (1) changes in ability to perform the movement; (2) withdrawals from the trial (see Fig. A, online supplementary material); and (3) technical issues (as detailed above). At baseline, all movement quality data were missing for two CPT participants and one CPT + MPT participant; thus, data were available for 49/52 (94\%) participants. At outcome, there were 66 participants but data were missing for: smoothness (two CPT participants and one CPT + MPT participant); co-ordination (one CPT participant); symmetry (one CPT + MPT participant); and knee maximum velocity (two CPT participants and one CPT + MPT participant) (Table 3). At follow-up, all movement data were missing from one CPT + MPT participant, leaving data for 59/60 (98\%) participants. However, data were missing for: smoothness and co-ordination (two CPT participants); symmetry (one CPT participant and one CPT + FST participant); and knee maximum velocity (one CPT participant) (see Table 4 for details).

\section{<Insert Tables 3 and 4 near here>}


Group response to the interventions was compared at outcome (Table 3) and follow-up (Table 4). In summary, participants in both experimental groups showed similar responses to the CPT group. The only significant difference found was for symmetry during the rising phase for the CPT + MPT group at outcome (mean difference $0.14,95 \%$ CI 0.01 to $0.26, P=0.03$ ). There was only one other response that approached statistical significance, and that was for greater smoothness in the CPT + MPT group at outcome (mean difference $32,95 \% \mathrm{CI}-4.44$ to $68.4, P=0.08$ ).

\section{$<\mathrm{A}>$ Discussion}

All three groups improved their STS ability, with 60/68 (88\%) participants able to perform the movement at follow-up compared with only 52/93 (56\%) participants at baseline. Examination of the added effect of extra MPT or FST to routine CPT found ORs indicating benefit, but these were accompanied by wide $95 \%$ CIs and are therefore imprecise. Consequently, there could be a large effect on an individual's recovery of the STS task by providing extra therapy in the form of either CPT or FST. Equally, however, there could have been a detrimental effect. For those participants able to perform the STS task, their movement quality was investigated. No benefits were found for either duration of the entire movement, or phase of flexion momentum through augmentation of routine CPT with either MPT or FST. Likewise, no differences were found for co-ordination, symmetry at the end of the movement, or maximum angular velocity of the paretic knee. Symmetry during rising did, however, show a significant improvement in one group when compared with CPT alone. The CPT + MPT group improved $(P=0.03)$ at outcome, but this benefit did not persist at follow-up $(P=0.69)$. These results should be considered in the context of high data variability.

The findings of this STS-focused investigation contrast with those from the same trial that indicated benefits for walking and knee flexion muscle strength for the CPT + MPT group compared with the CPT group [8]. The wide CIs around ORs for ability to STS and the 95\% CIs around mean differences for movement quality suggest that this inconsistency may relate to greater interindividual differences in the STS task compared with the walking task. A possible reason for this heterogeneity 
could be because stroke survivors employ the degrees of freedom available in the residual neural system to be able to STS using different movement strategies $[19,20]$ to overcome the high motor demands of the movement [2]. Indeed, this high variability is characteristic of movement studies, particularly in a heterogeneous population and given the natural variability in human movement [21].

Interestingly, the findings suggest that the provision of extra therapy did not add to the benefits of routine CPT for recovery of STS. This was unexpected as there is evidence that additional therapy is beneficial [22]. It is possible that the additional therapy did not produce benefits for STS because, according to reports, at least 16 hours are required [22] and participants in the experimental groups did not reach this threshold. However, this explanation is unlikely as significant benefits were reported for the CPT + MPT group for walking speed. It is also possible that heterogeneity in the STS response to the experimental interventions and the relatively small sample size meant that the study was underpowered, rather than the extra therapy not being beneficial.

The greater improvement in symmetry while rising found in the CPT + MPT group may relate to more emphasis being placed on this performance characteristic during therapy sessions [23]. A more symmetrical load distribution during rising is clearly desirable, with implications for movement efficiency [24] and risk of falls [23] as well as being an indicator of improved motor control [24]. The loss of this improvement at follow-up contradicts the findings of a recent meta-analysis [25]; the development of compensatory mechanisms in the absence of therapist feedback during the period between outcome and follow-up may explain this difference.

A reasonable conclusion from the finding of considerable heterogeneity in STS response is that different stroke survivors require different rehabilitation therapies for optimal recovery [26]. Motor learning is known to be influenced by the specificity of the training [27], so it may be that focusing on a single training task (e.g. the STS task) instead of a set of functional tasks (as per the study protocol) would have improved specific outcomes.

Heterogeneity is a feature of many rehabilitation trials, and this becomes particularly noticeable in meta-analysis [22] . Indeed, there is evidence that different interventions may not be suitable for all 
stroke survivors (e.g. constraint-induced therapy [28] and motor imagery [11]). Such findings have shaped the concept of personalised stroke rehabilitation [29] and differential prognosis [30].

A limitation of the investigation reported here was the relatively high attrition rate at follow-up (28\%). However, the attrition rate at the primary end-point of outcome (end of the 6-week intervention phase) was only $11 \%$, and the attrition rate at both time points was comparable to other randomised controlled trials in stroke rehabilitation [31].

Another element reducing the sample size available for analysis was that the quality of movement metrics were not collected for a small number of participants able to perform the movement because of technical issues during data collection. Such challenges are not uncommon in clinical biomechanics studies [32], highlighting the practical issues surrounding the use of complex measurement systems and therefore the need for measurement technologies tailored for rehabilitation settings.

A strength of the investigation reported here is the objective measurement of movement quality during an everyday functional task, and thus of direct relevance to clinical practice. Until recently, changes in quality of movement have been measured subjectively [33]. Although unable to capture the full complexity of the STS movement, these objective metrics signal progress towards tools that will allow robust investigation of the recovery process after stroke and, in particular, the influence of rehabilitation. The use of these metrics in this study identified the lack of difference in quality of movement changes between a therapy focused on enhancing recovery by concentrating on the quality of movement (MPT), and one that emphasised strength training and repetitive task-specific practice (FST). These results thus add to the evidence negating clinical concerns that concentrating on the provision of FST will be at the expense of movement quality [33,34].

The quality of movement measurements reported here requires the use of technically advanced equipment, and is therefore likely to remain beyond many healthcare budgets. However, advances in body-worn sensors [35] and video processing technology [36] promise low-cost motion analysis that could include measurement of movement quality [18]. The use of these systems is beginning to be 
accepted in rehabilitation research [36]. Capturing this end-product of neural activity in patients after a stroke has the potential to cause a step change in understanding of stroke rehabilitation. Recently, changes in brain activation, as measured by near-infra-red spectroscopy, have been found to be significantly correlated with improvements in biomechanical measures of gait [37], giving further validation to this biomechanical approach.

\section{$<\mathrm{A}>$ Conclusion}

The ability to perform the STS task recovers with rehabilitation in the majority of stroke patients. Functional recovery matched changes in quality of movement: timing, symmetry, co-ordination and smoothness. The lack of statistical difference suggests that the emphasis of therapy (conventional, MPT or FST) has little bearing on outcome.

Ethical approval: The local research ethics committees covering the clinical centres granted ethical approval. The trial was registered on a clinical trials database (NCT00322192).

Funding: The Healthcare Foundation.

Conflict of interest: None declared.

\section{$<$ A $>$ References}

[1] Grant PM, Dall PM, Kerr A. Daily and hourly frequency of the sit to stand movement in older adults: a comparison of day hospital, rehabilitation ward and community living groups. Aging Clin Exp Res 2011;23:437-44.

[2] Bohannon RW. Measurement of sit-to-stand among older adults. Top Geriatr Rehabil 2012;28:11-6.

[3] $\mathrm{Ng} \mathrm{S}$. Balance ability, not muscle strength and exercise endurance, determines the performance of hemiparetic subjects on the timed-sit-to-stand test. Am J Phys Med Rehabil 2010;89:497-504 
[4] Scottish Intercollegiate Guidelines Network. Management of patients with stroke: rehabilitation, prevention and management of complications, and discharge planning. SIGN: Edinburgh; 2010.

[5] French B, Thomas LH, Leathley MJ, Sutton CJ, McAdam J, Forster A, et al. Repetitive task training for improving functional ability after stroke. Cochrane Database Syst Rev 2007;4:CD006073.

[6] Arya KN, Verma R, Garg RK, Sharma VP, Agarwal M, Aggarwal GG. Meaningful task-specific training (MTST) for stroke rehabilitation: a randomized controlled trial. Top Stroke Rehabil 2012;19:193-211.

[7] Donaldson C, Tallis R, Miller S, Sunderland A, Lemon R, Pomeroy V. Effects of conventional physical therapy and functional strength training on upper limb motor recovery after stroke: a randomized phase II study. Neurorehabil Neural Repair 2009;23:389-97.

[8] Cooke EV, Tallis RC, Clark A, Pomeroy VM. Efficacy of functional strength training on restoration of lower-limb motor function early after stroke: phase I randomized controlled trial. Neurorehabil Neural Repair 2010;24:88-96.

[9] Yang YR, Wang RY, Lin KH, Chu MY, Chan RC. Task-oriented progressive resistance strength training improves muscle strength and functional performance in individuals with stroke. Clin Rehabil 2006;20:860-70.

[10] Vaughan-Graham J, Cott C, Wright FV. The Bobath (NDT) concept in adult neurological rehabilitation: what is the state of the knowledge? A scoping review. Part I: conceptual perspectives. Disabil Rehabil 2015;37:1793-807.

[11] Langhorne P, Bernhardt J, Kwakkel G. Stroke rehabilitation. Lancet 2011;377:1693-702.

[12] Geroin C, Mazzoleni S, Smania N, Gandolfi M, Bonaiuti D, Gasperini G; Italian Robotic Neurorehabilitation Research Group. Systematic review of outcome measures of walking training using electromechanical and robotic devices in patients with stroke. J Rehabil Med 2013;45:987-96.

[13] Pomeroy VM, Cooke E, Hamilton S, Whittet A, Tallis RC. Development of a schedule of current physiotherapy treatment used to improve movement control and functional use of the lower limb after stroke: a precursor to a clinical trial. Neurorehabil Neural Repair 2005;19:350-9. 
[14] Summan R, Pierce SG, Macleod CN, Dobie G, Gears T,Lester W, et al. Spatial calibration of large volume photogrammetry based metrology systems. Measurement 2015;68:189-200.

[15] Meldrum D, Shouldice C, Conroy R, Jones K, Forward M. Test-retest reliability of three dimensional gait analysis: including a novel approach to visualising agreement of gait cycle waveforms with Bland and Altman plots. Gait Posture 2014;39:265-71.

[16] Qi A, et al. Generation of human standing-up motion with muscle synergies using forward dynamic simulation. 2014 IEEE International Conference on Robotics and Automation (ICRA), Hong Kong, 31 May-5 June 2014.

[17] Celik O, O'Malley MK, Boake C, Levin HS, Yozbatiran N, Reistetter TA. Normalized movement quality measures for therapeutic robots strongly correlate with clinical motor impairment measures. IEEE Trans Neural Syst Rehabil Eng 2010;18:433-4.

[18] Kerr A, Pomeroy VP, Rowe PJ, Dall P, Rafferty D. Measuring movement fluency during the sit-to-walk task. Gait Posture 2013;37:598-602.

[19] Scholz JP, Schöner G. The uncontrolled manifold concept: identifying control variables for a functional task. Exp Brain Res 1999;126:289-306.

[20] Richards JD, Pramanik A, Sykes L, Pomeroy VM. A comparison of knee kinematic characteristics of stroke patients and age-matched healthy volunteers. Clin Rehabil 2003;17:565-71.

[21] McGinley $\mathbf{J}$, et al. Variability of walking in able-bodied adults across different time intervals. J Phys Med Rehabil Sci 2014;17:6-10.

[22] Kwakkel G, van Peppen R, Wagenaar RC, Wood Dauphinee S, Richards C, Ashburn A, et al. Effects of augmented exercise therapy time after stroke: a meta-analysis. Stroke 2004;35:2529-39.

[23] Pollock A, Gray C, Culham E, Durward BR, Langhorne P. Interventions for improving sit-to-stand ability following stroke. Cochrane Database Syst Rev 2014;5:CD007232.

[24] Liu M, Chen J, Fan W, Mu J, Zhang J, Wang L, et al. Effects of modified sit-to-stand training on balance control in hemiplegic stroke patients: a randomized controlled trial. Clin Rehabil 2015; Aug 27. pii: 0269215515600505 [Epub ahead of print]. 
[25] Pollock A, Gray C, Culham E, Durward BR, Langhorne P. Interventions for improving sit-to-stand ability following stroke. Cochrane Database Syst Rev 2014;5:CD007232.

[26] Pomeroy VM, Tallis RC. Need to focus research in stroke rehabilitation. Lancet 2000;355:836-7.

[27] Bayona NA, Bitensky J, Salter K, Teasell R. The role of task-specific training in rehabilitation therapies. Top Stroke Rehabil 2005;12:58-65.

[28] Kwakkel G, Veerbeek JM, van Wegen EE, Wolf SL. Constraint-induced movement therapy after stroke. Lancet Neurol 2015;14:224-34.

[29] van Vliet P, Carey L, Nilsson M. Targeting stroke treatment to the individual. Int J Stroke 2012;7:480-1.

[30] Stinear CM, Ward NS. How useful is imaging in predicting outcomes in stroke rehabilitation? Int $\mathbf{J}$ Stroke 2013;8:33-7.

[31] Thrane G, Askim T, Stock R, Indredavik B, Gjone R, Erichsen A, et al. Efficacy of constraint-induced movement therapy in early stroke rehabilitation: a randomized controlled multisite trial. Neurorehabil Neural Repair 2015;29:517-25.

[32] Combs SA, Dugan EL, Ozimek EN, Curtis AB. Bilateral coordination and gait symmetry after bodyweight supported treadmill training for persons with chronic stroke. Clin Biomech 2013;28:448-53.

[33] Langhammer B, Stanghelle JK. Can physiotherapy after stroke based on the Bobath concept result in improved quality of movement compared to the motor relearning programme. Physiother Res Int 2011;16:69-80.

[34] Lennon S, Baxter D, Ashburn A. Physiotherapy based on the Bobath concept in stroke rehabilitation: a survey within the UK. Disabil Rehabil 2001;23:254-62.

[35] Spain RI, Mancini M, Horak FB, Bourdette D. Body-worn sensors capture variability, but not decline, of gait and balance measures in multiple sclerosis over 18 months. Gait Posture 2014;39:958-64.

[36] Ugbolue UC, Papi E, Kaliarntas KT, Kerr A, Earl L, Pomeroy VM, et al. The evaluation of an inexpensive, 2D, video based gait assessment system for clinical use. Gait Posture 2013;38:483-9.

[37] Miyai I, Suzuki M, Hatakenaka M, Kubota K. Effect of body weight support on cortical activation during gait in patients with stroke. Exp Brain Res 2006;169:85-91. 
Page 18 of 25 


\section{Table 1}

Baseline characteristics of all participants $(n=93)$, and those suitable for analysis $(n=49)$, according to randomised group allocation

\begin{tabular}{|l|c|c|c|}
\hline & \multicolumn{3}{|c|}{ All baseline $(n=93)$} \\
\hline & $\begin{array}{c}\text { CPT } \\
(n=32)\end{array}$ & $\begin{array}{c}\text { CPT + MPT } \\
(n=31)\end{array}$ & $\begin{array}{c}\text { CPT + FST } \\
(n=30)\end{array}$ \\
\hline Age (years) & $66.3($ SD 14.3) & 68.9 (SD 10.6) & 71.1 (SD 10.8) \\
\hline Time since stroke (days) & $36.4($ SD 24.0) & $30.4($ SD 21.1) & 33.7 (SD 23.5) \\
\hline Neglect present $(n=20)$ & $6(19)$ & $7(23)$ & $7(23)$ \\
\hline Male $(n=54)$ & $17(53)$ & $20(64)$ & $17(57)$ \\
\hline Side of stroke lesion (left, $n=47)$ & $14(44)$ & $15(48)$ & $18(60)$ \\
\hline Able to perform STS $(n=52)$ & $20(63)$ & $16(52)$ & $16(53)$ \\
\hline & \multicolumn{3}{|c|}{ Suitable for analysis $(n=49)$} \\
\hline & CPT & CPT + MPT & CPT + FST \\
& $(n=18)$ & $(n=15)$ & $(n=16)$ \\
\hline Age (years) & $59.9($ SD 15.7) & $66.3($ SD 12.5) & $69.9($ SD 10.0) \\
\hline Time since stroke (days) & $29.4($ SD 21.9) & $26.1($ SD 19.0) & $29.5($ SD 15.1) \\
\hline Neglect present $(n=6)$ & $3(17)$ & $1(7)$ & $2(13)$ \\
\hline Male $(n=30)$ & $9(50)$ & $11(73)$ & $10(62)$ \\
\hline Side of stroke lesion (left, $n=28)$ & $10(56)$ & $9(60)$ & $9(56)$ \\
\hline
\end{tabular}

CPT, conventional physical therapy; MPT, movement performance therapy; FST, functional strength training; STS, sit to stand; SD, standard deviation. 
Table 2

Comparison of ability to perform the sit-to-stand movement: odds ratio of ability at outcome and follow up compared with conventional physical therapy (CPT)

\begin{tabular}{|l|c|c|c|c|c|c|}
\hline & $\begin{array}{c}\text { All } \\
\text { participants }\end{array}$ & CPT & \multicolumn{2}{|c|}{ CPT + MPT } & \multicolumn{2}{c|}{ CPT + FST } \\
\hline & Able & Able & Able & $\begin{array}{c}\text { Odds } \\
\text { ratio } \\
(95 \% \mathrm{Cl})\end{array}$ & Able & $\begin{array}{c}\text { Odds } \\
\text { ratio } \\
(95 \% \mathrm{Cl})\end{array}$ \\
\hline Baseline & $52 / 93,56 \%$ & $20 / 32,63 \%$ & $16 / 31,52 \%$ & $\mathrm{NA}$ & $16 / 30,53 \%$ & $\mathrm{NA}$ \\
\hline Outcome & $66 / 84,79 \%$ & $19 / 27,70 \%$ & $22 / 27,81 \%$ & $\begin{array}{c}1.85(0.52 \\
\text { to } 6.63)\end{array}$ & $25 / 30,83 \%$ & $\begin{array}{c}2.11(0.59 \\
\text { to } 7.47)\end{array}$ \\
\hline $\begin{array}{l}\text { Follow- } \\
\text { up }\end{array}$ & $60 / 68,88 \%$ & $18 / 19,95 \%$ & $20 / 24,83 \%$ & $\begin{array}{c}0.28(0.03 \\
\text { to } 2.72)\end{array}$ & $22 / 25,88 \%$ & $\begin{array}{c}0.41(0.04 \\
\text { to } 4.26)\end{array}$ \\
\hline
\end{tabular}

MPT, movement performance therapy; FST, functional strength training; NA, not available; Cl, confidence interval. 
Table 3

Quality of movement metrics for sit-to-stand at baseline, outcome and follow-up

\begin{tabular}{|c|c|c|c|c|c|c|c|c|c|}
\hline \multirow[t]{2}{*}{ Metric } & \multicolumn{3}{|c|}{ Baseline $(n=49)$} & \multicolumn{3}{|c|}{ Outcome $(n=66)$} & \multicolumn{3}{|c|}{ Follow-up $(n=59)$} \\
\hline & $\begin{array}{c}\mathrm{CPT} \\
(n=18)\end{array}$ & $\begin{array}{c}\mathrm{CPT}+\mathrm{MPT} \\
(n=15)\end{array}$ & $\begin{array}{c}\mathrm{CPT}+\mathrm{FST} \\
(n=16)\end{array}$ & $\begin{array}{c}\mathrm{CPT} \\
(n=19)\end{array}$ & $\begin{array}{c}\mathrm{CPT}+\mathrm{MPT} \\
(n=22)\end{array}$ & $\begin{array}{c}\mathrm{CPT}+\mathrm{FST} \\
(n=25)\end{array}$ & $\begin{array}{c}\text { CPT } \\
(n=18)\end{array}$ & $\begin{array}{c}\mathrm{CPT}+\mathrm{MPT} \\
(n=19)\end{array}$ & $\begin{array}{c}\mathrm{CPT}+\mathrm{FST} \\
(n=22)\end{array}$ \\
\hline $\begin{array}{l}\text { Movement duration } \\
\text { (seconds) }\end{array}$ & $\begin{array}{c}3.11 \\
(1.49)\end{array}$ & $\begin{array}{c}3.07 \\
(1.76)\end{array}$ & $\begin{array}{c}2.91 \\
(1.54)\end{array}$ & $\begin{array}{c}2.96 \\
(1.95)^{a}\end{array}$ & $\begin{array}{c}2.88 \\
(1.69)\end{array}$ & $\begin{array}{c}2.89 \\
(1.44)\end{array}$ & $\begin{array}{c}3.01 \\
(1.94)\end{array}$ & $\begin{array}{c}2.89 \\
(1.99)\end{array}$ & $\begin{array}{c}2.62 \\
(1.32)\end{array}$ \\
\hline $\begin{array}{l}\text { Flexion momentum } \\
\text { duration (seconds) }\end{array}$ & $\begin{array}{c}1.35 \\
(0.84)\end{array}$ & $\begin{array}{c}1.26 \\
(1.11)\end{array}$ & $\begin{array}{c}1.03 \\
(0.55)\end{array}$ & $\begin{array}{c}1.17 \\
(0.86)\end{array}$ & $\begin{array}{c}1.19 \\
(1.14)\end{array}$ & $\begin{array}{c}1.16 \\
(0.75)\end{array}$ & $\begin{array}{c}1.22 \\
(0.98)\end{array}$ & $\begin{array}{c}1.02 \\
(1.14)\end{array}$ & $\begin{array}{l}1.04 \\
(0.7)\end{array}$ \\
\hline $\begin{array}{l}\text { Smoothness } \\
\text { (inflection count) }\end{array}$ & $\begin{array}{c}57.52 \\
(62.52)\end{array}$ & $\begin{array}{c}50.37 \\
(36.83)\end{array}$ & $\begin{array}{c}68.67 \\
(76.19)\end{array}$ & $\begin{array}{c}35.16 \\
\left(45.07^{b}\right.\end{array}$ & $\begin{array}{c}67.12 \\
(67.45)^{a}\end{array}$ & $\begin{array}{c}55.57 \\
(50.22)\end{array}$ & $\begin{array}{c}49.23 \\
(55.63)^{b}\end{array}$ & $\begin{array}{c}66.61 \\
(63.79)\end{array}$ & $\begin{array}{c}59.31 \\
(67.39)\end{array}$ \\
\hline $\begin{array}{l}\text { Co-ordination } \\
\text { (temporal overlap, } \\
\text { percentage) }\end{array}$ & $\begin{array}{c}9.7 \\
(9.63)\end{array}$ & $\begin{array}{c}9.99 \\
(8.33)\end{array}$ & $\begin{array}{c}15.1 \\
(14.29)\end{array}$ & $\begin{array}{c}15.28 \\
(8.93)^{\mathrm{a}}\end{array}$ & $\begin{array}{c}14.25 \\
(10.66)\end{array}$ & $\begin{array}{c}12.67 \\
(10.61)\end{array}$ & $\begin{array}{c}15.73 \\
(6.73)^{b}\end{array}$ & $\begin{array}{l}13.78 \\
(7.43)\end{array}$ & $\begin{array}{c}14.77 \\
(10.26)\end{array}$ \\
\hline $\begin{array}{l}\text { Symmetry when rising } \\
\text { (affected/unaffected) }\end{array}$ & $\begin{array}{l}-0.27 \\
(0.2)\end{array}$ & $\begin{array}{l}-0.17 \\
(0.14)\end{array}$ & $\begin{array}{l}-0.18 \\
(0.18)\end{array}$ & $\begin{array}{c}0.15 \\
(0.24)\end{array}$ & $\begin{array}{l}-0.02 \\
(0.12)^{\mathrm{a}}\end{array}$ & $\begin{array}{l}-0.11 \\
(0.21)\end{array}$ & $\begin{array}{l}-0.13 \\
(0.2)^{\mathrm{a}}\end{array}$ & $\begin{array}{l}-0.1 \\
(0.2)\end{array}$ & $\begin{array}{l}-0.15 \\
(0.18)^{a}\end{array}$ \\
\hline $\begin{array}{l}\text { Symmetry at end of } \\
\text { movement } \\
\text { (affected/unaffected) }\end{array}$ & $\begin{array}{l}-0.16 \\
(0.34)\end{array}$ & $\begin{array}{l}-0.18 \\
(0.19)\end{array}$ & $\begin{array}{c}-0.1 \\
(0.24)\end{array}$ & $\begin{array}{l}-0.13 \\
(0.24)\end{array}$ & $\begin{array}{c}-0.04 \\
(0.19)^{\mathrm{a}}\end{array}$ & $\begin{array}{l}-0.22 \\
(0.30)\end{array}$ & $\begin{array}{c}-0.07 \\
(0.24)^{a}\end{array}$ & $\begin{array}{c}-0.1 \\
(0.22)\end{array}$ & $\begin{array}{c}-0.14 \\
(0.25)^{\mathrm{a}}\end{array}$ \\
\hline $\begin{array}{l}\text { Paretic knee maximum } \\
\text { angular velocity } \\
\text { (degrees/second) }\end{array}$ & $\begin{array}{l}115.84 \\
(54.15)\end{array}$ & $\begin{array}{l}130.48 \\
(59.42)\end{array}$ & $\begin{array}{l}110.81 \\
(49.68)\end{array}$ & $\begin{array}{l}104.13 \\
(50.6)^{b}\end{array}$ & $\begin{array}{c}130.19 \\
(91.99)^{a}\end{array}$ & $\begin{array}{l}105.64 \\
(35.81)\end{array}$ & $\begin{array}{c}148.4 \\
(141.41)^{a}\end{array}$ & $\begin{array}{l}109.76 \\
(45.12)\end{array}$ & $\begin{array}{l}115.28 \\
(43.26)\end{array}$ \\
\hline
\end{tabular}

CPT, conventional physical therapy; MPT, movement performance therapy; FST, functional strength training.

${ }^{a}$ Missing data from one participant, ${ }^{b}$ missing data from two participants. Data incomplete due to technical issues with motion capture (>15 frame gaps in trajectories) and/or forceplate errors. 
Table 4

Response from baseline compared with conventional physical therapy (CPT)

\begin{tabular}{|c|c|c|c|c|c|c|c|c|}
\hline \multirow[t]{3}{*}{ Metric } & \multicolumn{4}{|c|}{ Response at outcome } & \multicolumn{4}{|c|}{ Response at follow-up } \\
\hline & \multicolumn{2}{|c|}{$\mathrm{CPT}+\mathrm{MPT}$} & \multicolumn{2}{|c|}{$\mathrm{CPT}+\mathrm{FST}$} & \multicolumn{2}{|c|}{$\mathrm{CPT}+\mathrm{MPT}$} & \multicolumn{2}{|c|}{$\mathrm{CPT}+\mathrm{FST}$} \\
\hline & $\begin{array}{c}\text { Mean } \\
\text { difference } \\
(95 \% \mathrm{Cl})\end{array}$ & $P$-value & $\begin{array}{c}\text { Mean } \\
\text { difference } \\
(95 \% \mathrm{Cl})\end{array}$ & $P$-value & $\begin{array}{c}\text { Mean } \\
\text { difference } \\
(95 \% \mathrm{Cl}) \\
\end{array}$ & $P$-value & $\begin{array}{c}\text { Mean } \\
\text { difference } \\
(95 \% \mathrm{Cl})\end{array}$ & $P$-value \\
\hline Movement duration (seconds) & $\begin{array}{c}-0.08 \\
(-1.16 \text { to } 0.99)\end{array}$ & 0.89 & $\begin{array}{c}-0.08 \\
(-1.11 \text { to } 0.96)\end{array}$ & 0.88 & $\begin{array}{c}-0.19 \\
(-0.82 \text { to } \\
0.43)\end{array}$ & 0.53 & $\begin{array}{c}-0.18 \\
(-0.79 \text { to } 0.43)\end{array}$ & 0.56 \\
\hline $\begin{array}{l}\text { Flexion momentum duration } \\
\text { (seconds) }\end{array}$ & $\begin{array}{c}0.02 \\
(-0.57 \text { to } 0.62)\end{array}$ & 0.94 & $\begin{array}{c}-0.01 \\
(-0.59 \text { to } 0.56)\end{array}$ & 0.96 & $\begin{array}{c}-0.12 \\
(-1.30 \text { to } \\
1.05)\end{array}$ & 0.83 & $\begin{array}{c}-0.39 \\
(-1.52 \text { to } 0.74)\end{array}$ & 0.49 \\
\hline $\begin{array}{l}\text { Smoothness } \\
\text { (inflection count) }\end{array}$ & $\begin{array}{c}32.0 \\
(-4.44 \text { to } \\
68.40)\end{array}$ & 0.08 & $\begin{array}{c}20.40 \\
(-14.3 \text { to } 55.1)\end{array}$ & 0.24 & $\begin{array}{c}17.40 \\
(-25.5 \text { to } \\
60.3)\end{array}$ & 0.42 & $\begin{array}{c}10.10 \\
(-31.9 \text { to } 52.0)\end{array}$ & 0.63 \\
\hline $\begin{array}{l}\text { Co-ordination } \\
\text { (temporal overlap, percentage) }\end{array}$ & $\begin{array}{c}-1.03 \\
(-7.57 \text { to } 5.51)\end{array}$ & 0.75 & $\begin{array}{c}-2.60 \\
(-8.90 \text { to } 3.69)\end{array}$ & 0.41 & $\begin{array}{c}-1.95 \\
(-7.69 \text { to } \\
3.80) \\
\end{array}$ & 0.50 & $\begin{array}{c}-0.96 \\
(-6.58 \text { to } 4.66)\end{array}$ & 0.73 \\
\hline $\begin{array}{l}\text { Symmetry when rising } \\
\text { (affected/unaffected) }\end{array}$ & $\begin{array}{c}0.14 \\
(0.012 \text { to } 0.26)\end{array}$ & 0.03 & $\begin{array}{c}0.04 \\
(-0.076 \text { to } \\
0.16)\end{array}$ & 0.47 & $\begin{array}{c}0.03 \\
(-0.11 \text { to } \\
0.16) \\
\end{array}$ & 0.69 & $\begin{array}{c}-0.02 \\
(-0.15 \text { to } 0.11)\end{array}$ & 0.75 \\
\hline $\begin{array}{l}\text { Symmetry at end of movement } \\
\text { (affected/unaffected) }\end{array}$ & $\begin{array}{c}0.09 \\
(-0.07 \text { to } 0.25)\end{array}$ & 0.24 & $\begin{array}{c}-0.09 \\
(-0.25 \text { to } 0.06)\end{array}$ & 0.23 & $\begin{array}{c}-0.04 \\
(-0.20 \text { to } \\
0.12)\end{array}$ & 0.65 & $\begin{array}{c}-0.07 \\
(-0.23 \text { to } \\
0.091)\end{array}$ & 0.39 \\
\hline $\begin{array}{l}\text { Paretic knee maximum angular } \\
\text { velocity (degrees/second) }\end{array}$ & $\begin{array}{c}26.10 \\
(-67.3 \text { to } 15.2)\end{array}$ & 0.21 & $\begin{array}{c}1.51 \\
(-41.7 \text { to } 38.7)\end{array}$ & 0.94 & $\begin{array}{c}20.20 \\
(-55.3 \text { to } \\
15.0)\end{array}$ & 0.25 & $\begin{array}{c}11.50 \\
(-45.9 \text { to } 22.9)\end{array}$ & 0.50 \\
\hline
\end{tabular}

MPT, movement performance therapy; FST, functional strength training; NA, not available; $\mathrm{Cl}$, confidence interval. 


\section{Copyedit Queries}

Ref: PHYST

Author:

\begin{tabular}{|l|l|}
\hline Query & Response \\
\hline $\begin{array}{l}\text { [Au?1] Data capture and processing; 'Maximum knee angular velocity - defined as } \\
\text { the maximum value from the software output (Oxford Metrics, Oxford) of the first }\end{array}$ & \\
derivative the paretic side knee angle between onset and end.' Please clarify & \\
\hline $\begin{array}{l}\text { [Au?2] Refs 16, 21 - please list first six authors followed by 'et al' (or all authors if } \\
\text { there are six or fewer) }\end{array}$ & \\
\hline [Au?3] Ref 24 - please update if possible & \\
\hline $\begin{array}{l}\text { [Au?4] Ethical approval - please supply names of local research ethics committees, } \\
\text { and reference numbers given to the trial }\end{array}$ & \\
\hline [Au?5] & \\
\hline
\end{tabular}

Unless specifically requested, please do not supply a modified manuscript; either provide an answer to each question or supply the requested section of the manuscript. 
Consort checklist

Click here to download Supplementary online only: CONSORT Checklist_FST_Physiotherapy.doc

Page 24 of 25 
only: Fig A - online only.docx

\section{Page 25 of 25}

( 